ARTICLE

\title{
Photobiocatalytic synthesis of chiral secondary fatty alcohols from renewable unsaturated fatty acids
}

\author{
Wuyuan Zhang (10 1,2,6, Jeong-Hoo Lee ${ }^{3,6}$, Sabry H. H. Younes ${ }^{1,4}$, Fabio Tonin', Peter-Leon Hagedoorn (1) 1, \\ Harald Pichler (D) ${ }^{5}$, Yoonjin Baeg ${ }^{3}$, Jin-Byung Park ${ }^{3 凶}$, Robert Kourist (1) ${ }^{5 凶}$ \& Frank Hollmann (1) ${ }^{1 凶}$
}

En route to a bio-based chemical industry, the conversion of fatty acids into building blocks is of particular interest. Enzymatic routes, occurring under mild conditions and excelling by intrinsic selectivity, are particularly attractive. Here we report photoenzymatic cascade reactions to transform unsaturated fatty acids into enantiomerically pure secondary fatty alcohols. In a first step the $\mathrm{C}=\mathrm{C}$-double bond is stereoselectively hydrated using oleate hydratases from Lactobacillus reuteri or Stenotrophomonas maltophilia. Also, dihydroxylation mediated by the 5,8-diol synthase from Aspergillus nidulans is demonstrated. The second step comprises decarboxylation of the intermediate hydroxy acids by the photoactivated decarboxylase from Chlorella variabilis NC64A. A broad range of (poly)unsaturated fatty acids can be transformed into enantiomerically pure fatty alcohols in a simple one-pot approach.

\footnotetext{
${ }^{1}$ Department of Biotechnology, Delft University of Technology, Van der Maasweg 9, $2629 \mathrm{HZ}$ Delft, The Netherlands. ${ }^{2}$ School of Chemical Engineering and Technology, Xi'an Jiaotong University, 710049 Xi'an, China. ${ }^{3}$ Department of Food Science \& Engineering, Ewha Womans University, Seoul 03760, Republic of Korea. ${ }^{4}$ Chemistry Department, Faculty of Science, Sohag University, Sohag 82524, Egypt. ${ }^{5}$ Institute of Molecular Biotechnology, Graz University of Technology, Petersgasse 14, 8010 Graz, Austria. ${ }^{6}$ These authors contributed equally: Wuyuan Zhang, Jeong-Hoo Lee. ${ }^{凶}$ email: jbpark06@ewha.ac.kr; kourist@tugraz.at; f.hollmann@tudelft.nl
} 
E nvisioning a biobased chemical industry, there is an increasing interest in the transformation of biomass-derived starting materials into chemical building blocks ${ }^{1,2}$. Natural fatty acids are particularly interesting building blocks, especially if derived from agricultural wastes or non-edible sources. Until recently, chemical methodologies for the conversion of fatty acids or their glycerides have been largely restricted to their (trans) esterification for the production of biodiese ${ }^{3}$ or cosmetic esters ${ }^{4}$. This situation is changing dramatically with various research groups developing new chemistries to valorise fatty acids (Fig. 1).

For example, with the discovery of the fatty acid decarboxylase Ole $^{5-7}$ or UndA $/ \mathrm{B}^{8}$, synthesis of terminal alkenes from fatty acids has come into reach ${ }^{6,9-12}$ giving access to chemical building blocks $^{13,14}$. Also the hydroxylation of fatty acids using P450 monooxygenases $^{15}$, per-oxygenases ${ }^{16,17}$ or dioxygenases ${ }^{18}$ is receiving increasing attention. The resulting hydroxy acids may be interesting building blocks for biobased and biodegradable polyesters. Oxyfunctionalisation of unsaturated fatty acids can also be achieved via selective water addition to the cis- $\mathrm{C}=\mathrm{C}$ double bond ${ }^{19,20}$ or via allylic hydroperoxidation ${ }^{21}$ followed by C-C-bond cleavage $\mathrm{e}^{22-27}$ or isomerisation to diols ${ }^{28,29}$. Also the selective reduction of the carboxylate group to either the alcohol or aldehyde moiety is possible ${ }^{30,31}$. Finally, the chemoenzymatic epoxidation of unsaturated fatty acids exploiting the 'perhydrolase' activity of lipases is worth mentioning ${ }^{32,33}$.

Long-chain secondary alcohols, which may be active ingredients in cosmetic formulations ${ }^{34,35}$, performance additives in oleochemicals or building blocks in natural product synthesis ${ }^{36}$ and for organic photosensitisers ${ }^{37}$, are currently not accessible from natural fatty acids. Established synthetic routes almost exclusively build on Grignard-type reactions of halide-derived nucleophiles with aldehydes or formic acid esters ${ }^{37}$, thereby necessitating multistep syntheses, leading to racemic products and generating significant amounts of salt wastes.

Recently, a decarboxylase from Chlorella variabilis NC64A $\left(C v\right.$ FAP) has been reported ${ }^{38}$, enabling the synthesis of alkanes from fatty acids 39,40 or the kinetic resolution of a-substituted acids $^{41}$. Compared to existing chemical decarboxylation pathways $^{42}, C v$ FAP appears particularly attractive due to the high chemoselectivity of the $C \nu \mathrm{FAP}$-reaction under mild reaction condition and its high-functional group tolerance (leaving $\mathrm{C}=\mathrm{C}$ double bonds and $\mathrm{OH}$-groups present in the starting material unaltered). $C \nu \mathrm{FAP}$ is a photoenzyme, i.e., its catalytic activity depends on the activation by light. More specifically, only the photoexcited flavin prosthetic group is sufficiently reactive for a single electron-transfer from the enzyme-bound carboxylate and thereby to initiate the decarboxylation reaction ${ }^{38}$.

Fascinated by the synthetic possibilities offered by $C v$ FAP we became interested in further elucidating its substrate scope and used it for the synthesis of functionalised alkane products (Scheme 2). We envision starting from unsaturated fatty acids, first introducing the alcohol functionality using either a fatty acid hydratase (Fig. 2, Cascade 1 or a diol synthase (Fig. 2, Cascade 2) followed by $C v$ FAP-catalysed decarboxylation.

\section{Results}

Design of the photoenzymatic cascades. The photoactivated carboxylic acid decarboxylase $C \nu \mathrm{FAP}$ was produced by recombinant expression in Escherichia coli following established protocols $^{38}$ (see Supplementary Methods) and used either as cell-free extracts or in whole cells. For the hydration of unsaturated fatty acids we first chose the oleate hydratase from Lactobacillus reuteri (LrOhyA). The synthetic gene encoding LrOhyA (Accession number: WP_109913811) was cloned into a pET28 vector and the enzyme was recombinantly expressed in E. coli BL21 (DE3) cells (Supplementary Fig. 1). Lyophilised cells containing LrOhyA were used for further reactions. It is worth mentioning here that empty E. coli cells (not containing any of the plasmids mentioned above) exhibited neither hydratase nor decarboxylation activity (Supplementary Fig. 5).

We first drew our attention to the hydratase/decarboxylase cascade, which indeed proceeded as envisioned. LrOhyA catalysed the hydration of oleic acid (Supplementary Fig. 6) followed by $C v \mathrm{FAP}$-catalysed decarboxylation of the intermediate

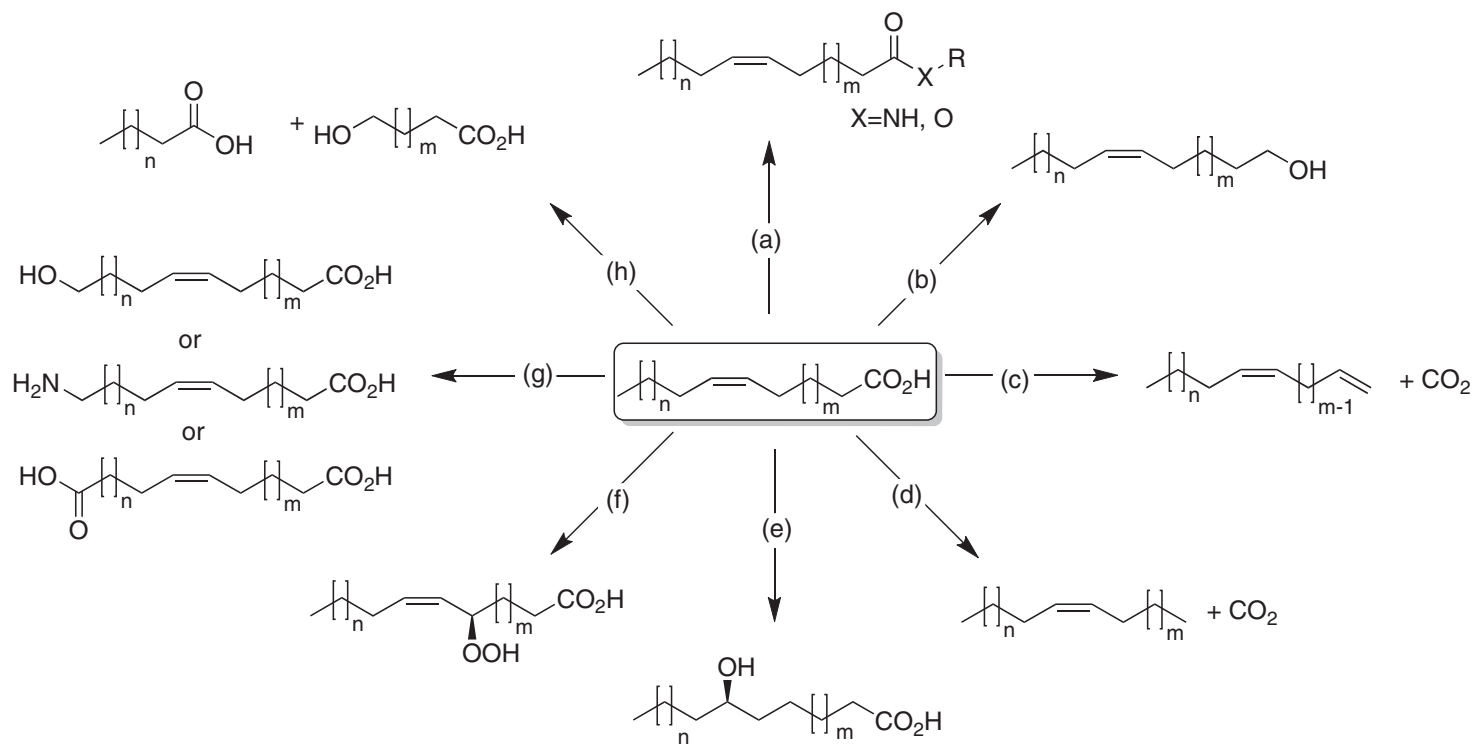

Fig. 1 Natural fatty acids as building blocks. In recent years, biocatalytic methodologies for the transformation of fatty acids have practically exploded. For example: a hydrolase-catalysed esterification of amidation ${ }^{4}, \mathbf{b}$ reductase-catalysed reduction of the carboxylate group to the corresponding aldehyde and alcohol 30,31 , c P450-peroxygenase-catalysed oxidative decarboxylation yielding terminal alkenes ${ }^{5-7}$, d photodecarboxylase-catalysed decarboxylation yielding alkanes ${ }^{38,39}$, e hydratase-catalysed water addition to $\mathrm{C}=\mathrm{C}$-bonds ${ }^{50}, \mathbf{f}$ lipoxygenase-catalysed allylic hydroperoxidation ${ }^{21}, \mathbf{g}$ use of mono-, di- and per-oxygenases for the terminal hydroxylation and further transformation into acids or amines as polymer building blocks ${ }^{15-18,51}$, and $\mathbf{h}$ multi-enzyme cascades yielding short-chain acids $22-27$. 


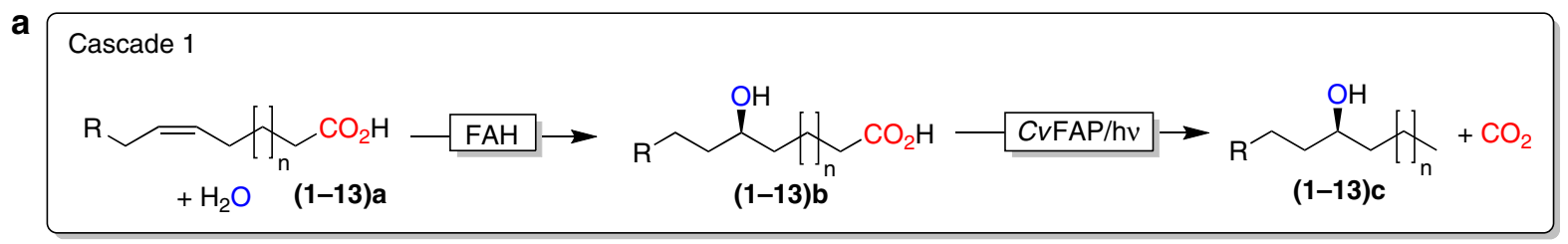

b

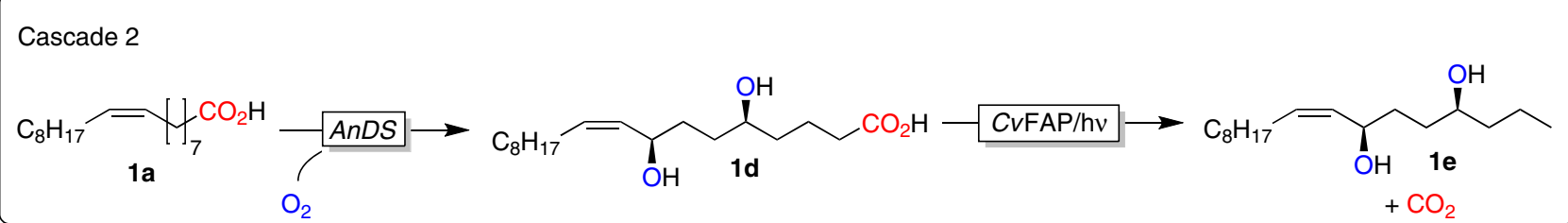

Fig. 2 Proposed photoenzymatic cascades to transform unsaturated fatty acids into secondary alcohols. a Cascade 1 comprises the (stereoselective) addition of water to $\mathrm{C}=\mathrm{C}$-double bonds catalysed by fatty acid hydratases (FAHs) followed by the decarboxylation mediated by the photoactivated decarboxylase from Chlorella variabilis NC64A (CVFAP) generating secondary long-chain alcohols; b cascade 2 combines 5,8-diol synthase from Aspergillus nidulans (AnDS) with CVFAP yielding diols.

hydroxy acid to yield 9-heptadecanol (Supplementary Fig. 7). To identify the factors influencing the product formation of the photoenzymatic cascade we further used oleate as model substrate. Using cell-free preparations of LrOhyA gave only low-product formation $(0.4 \mathrm{mM}$ of the desired 9-heptadecanol starting from oleic acid). We attribute this to a relative poor stability of LrOhyA under these conditions and therefore focussed using LrOhyA in lyophilised whole cells. It is also worth mentioning here that one-pot one-step procedures (i.e., performing the hydration and the decarboxylation reaction at the same time) predominantly yielded the decarboxylation product of oleic acid $((Z)$-heptadec-8-ene). Wild-type oleate hydratase requires a carboxylic acid function, which precludes hydration of $((Z)$ heptadec-8-ene ${ }^{43}$. Therefore, for all further experiments we followed a one-pot two-step procedure, i.e., first performing the hydration reaction followed by the addition of $C v \mathrm{FAP}$ to the reaction mixture and illumination to promote the decarboxylation reaction.

Full hydration of $7 \mathrm{mM}$ oleic acid (1a) was achieved within $11 \mathrm{~h}$ while the subsequent photoenzymatic decarboxylation was considerably faster (Fig. 3). A systematic variation of the reaction parameters (Supplementary Fig. 53) confirmed our initial assumption that LrOhyA represents the limiting factor in the catalytic cascade. Relatively high LrOhyA concentrations (lyophilised cells, $15-20 \mathrm{~g} \mathrm{~L}^{-1}$ ) were necessary to obtain full conversion of oleic acid into the desired product (1c) within the time frame of the experiment.

Investigating the substrate scope. Encouraged by this proof-ofconcept, we further investigated the substrate scope of the photoenzymatic cascade reaction. A broad range of (poly)unsaturated fatty acids were converted into the corresponding alcohols (Fig. 4 and Supplementary Figs. 8-48). Especially, $\Delta 9$-unsaturated fatty acids were converted in acceptable to good yields (24-74\%) into the corresponding alcohols. In those cases where poor conversion into the desired alcohols was observed, the hydration step was overall limiting (Supplementary Tables 1 and 2) and the corresponding unsaturated alkenes were the main products. We also investigated the optical purity of the corresponding products. Since commercial standards for most of the products were not available, we performed $\mathrm{O}$-acylation of the alcohol product using $(S)-(+)$-O-acetylmandelic acid for NMR analysis to determine their optical purity (Supplementary Fig. 49). Very pleasingly, in most cases, essentially enantiomerically pure products were obtained.

The cascade using linoleic acid (4a) was scaled-up (for details see preparative-scale synthesis in Supplementary Methods). From a semi-preparative transformation, overall $82.5 \mathrm{mg}(32.5 \%$ isolated yield) of the desired optically pure alcohol (4c) was obtained.

At this stage, we identified three major limitations of the current reaction system: (1) poor substrate loadings due to the poor solubility of the lipophilic fatty acid starting materials, (2) low overall reaction rates, especially of the hydration step, and (3) the need for two individual catalyst systems (OhyA and $C v$ FAP).

Use of two-liquid phase reactions. To address the solubility issue, we evaluated the well-established two-liquid system wherein a hydrophobic organic phase serves as substrate reservoir and product $\operatorname{sink}^{39}$. Given the fact, that the fatty acid substrates of interest are generally obtained from natural trigycerides, this appeared a suitable organic phase (Fig. 5). We evaluated this approach by using triolein as organic phase containing $20 \mathrm{mM}$ oleic acid. In this way, $17.4 \mathrm{mM}$ of 9-heptadecanol was obtained starting from $20 \mathrm{mM}$ of oleic acid dissolved in triolein (87\% yield, see Supplementary Table 3). The obvious next step was to extend the cascade by a hydrolase step to enable triglycerides as starting materials (Fig. 5). Again using triolein as organic phase the lipase from Candida rugosa (CrLip) catalysed the hydrolysis of the triglyceride while LrOhyA mediated the hydration of the $\mathrm{C}=\mathrm{C}$ double bond. After the illumination of the reaction mixture in the presence of $C \nu \mathrm{FAP}, 6.9 \mathrm{mM}$ of 9-heptadecanol was observed in the organic phase. In the current setup (devoid of external $\mathrm{pH}$ control), the hydrolysis of triolein was very fast, leading to an acidification of the aqueous layer, as confirmed by a $\mathrm{pH}$ paper test. As a consequence, the $C v \mathrm{FAP}$-catalysed decarboxylation slowed down considerably and the intermediate hydroxy acid represented the main product. We expect that higher product concentrations will be possible by controlling the $\mathrm{pH}$ of the reaction more stringently ${ }^{39}$.

Co-expression of both enzymes. Next, we addressed the low productivity issue as well as the need for two individual catalysts by constructing a co-expression system in E. coli. Instead of using LrOhyA we used the fatty acid hydratase from Stenotrophomonas maltophilia (SmOhyA), which had been reported to exhibit a very promising specific activity of $2.7 \mathrm{U} \mathrm{mg}^{-1}$ (refs. ${ }^{44,45}$ ). A previously optimised SmOhyA expression system in E. coli (i.e., 

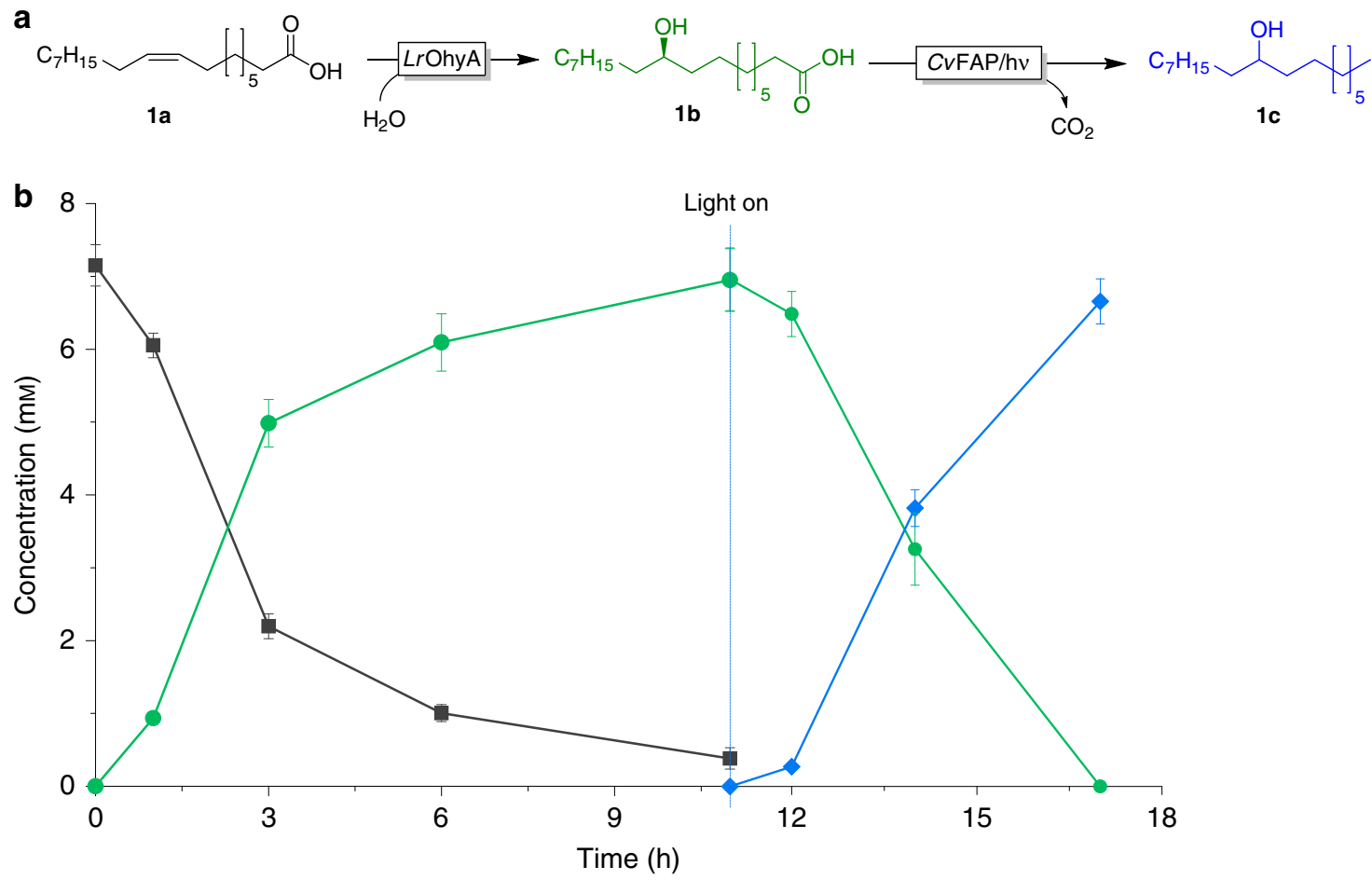

Fig. 3 Proposed photoenzymatic cascade to transform oleic acid into 9-heptadecanol. a: Recation scheme. $\mathbf{b}$ shows a representative time course of the cascade reaction. Reaction conditions: [oleic acid] $=7 \mathrm{mM},[$ LrOhyA cells $]=15 \mathrm{~g} \mathrm{~L}^{-1},[C v F A P]=2 \mu \mathrm{M}$, Tris- $\mathrm{HCl}$ buffer pH 8.0 (100 mM, with $50 \mathrm{mM}$ of $\mathrm{NaCl}$ ), illumination with blue light $\left(\lambda=450 \mathrm{~nm}\right.$; intensity $\left.=13.7 \mathrm{mE} \mathrm{L}^{-1} \mathrm{~s}^{-1}\right)$ : oleic acid (black squares), 10-hydroxystearic acid (green circles), 9heptadecanol (blue diamonds). Values represent the average of duplicates $(n=2)$. Error bars indicate the standard deviation.

pACYC-PelBSS-OhyA) ${ }^{46}$ was used as chassis for the recombinant expression of $C \nu \mathrm{FAP}$ (yielding a recombinant E. coli BL21 (DE3) pACYC-PelBSS-OhyA/pET28a-C $v$ FAP). Indeed co-overexpression of both enzymes was possible (Supplementary Fig. 4). We, therefore, used this catalyst for the combined hydration/decarboxylation of oleic acid yielding 9-heptadecene (1c, Fig. 6).

Despite the lower catalyst loading as compared to the experiment shown in Fig. $3\left(7 \mathrm{~g}_{\mathrm{CDW}} \mathrm{L}^{-1}\right.$ instead of $\left.15 \mathrm{~g}_{\mathrm{CDW}} \mathrm{L}^{-1}\right)$ a much higher hydration rate of oleic acid $\left(86 \mathrm{U} \mathrm{g}^{-1}{ }_{\mathrm{CDW}}\right)$ was observed resulting in more than $90 \%$ conversion of oleic acid into 10-hydroxyoctadecanoic acid (1b) within $7.5 \mathrm{~min}$ after which the decarboxylation reaction was initiated by commencing illumination of the reaction mixture with blue light. The rate of the decarboxylation was comparable with the rate shown in Fig. 3. It is worth mentioning that non-converted oleic acid was decarboxylated to $(Z)$-heptadec-8-ene.

Enlarging the scope of hydratases. In addition to the above-used fatty acid hydratases, a range of further fatty acid hydroxylating enzymes (e.g., linoleate 9S-lipoxygenase from Myxococcus xanthus $^{47}, 7,10$-diol synthase from Pseudomonas aeruginosa ${ }^{29}$, and 5,8-diol synthase from Aspergillus nidulans ${ }^{28}$ ) have been reported. The 5,8-diol synthase from A. nidulans (AnDS) for example caught our attention as this bifunctional enzyme adds two instead of only one $\mathrm{OH}$ functionalities into oleic acid by a two-step reaction (Fig. 7). Thereby, a three step cascade mediated by two enzymes was established for the preparation of $(Z)$-heptadec-8ene-4,7-diol (1e) from oleic acid.

For the dihydroxylation of oleic acid, 5,8-diol synthase from $A$. nidulans (AnDS) was used. The first recombinant $E$. coli expressing AnDS (E. coli BL21(DE3) pET21a-AnDS ${ }^{48}$, however, showed only poor $A n \mathrm{DS}$-activity (Supplementary Fig. 54(A)). Introduction of the signal sequence of PelB directed the enzyme into the periplasm ${ }^{46,49}$. Notably, E. coli BL21(DE3) pACYCPelBSS-AnDS displayed approximately 10-fold greater transformation rates and 2.3-fold higher final product concentration, as compared to the original strain E. coli BL21(DE3) pET21a-AnDS (Supplementary Fig. 54(B)). Having a suitable diol synthase and the photodecarboxylase at hand, we performed the conversion of oleic acid (Fig. 7). Already after $1 \mathrm{~h}, 95 \%$ of the starting material had been converted into the diol (1e). Initiating the decarboxylation reaction by illumination of the reaction mixture led to an abrupt decrease in all carboxylic acids present to the corresponding alkanes. The chemical identity of the final product as well as the intermediate hydroxy acid were confirmed via GC/MS (Supplementary Fig. 51) and NMR analytics (Supplementary Fig. 50).

Overall, in this contribution we have demonstrated that secondary fatty alcohols can be obtained from unsaturated fatty acids using a cascade of fatty acid hydratase or diol synthase and fatty acid decarboxylase. The substrate scope of the current system is fairly broad giving access to enantiomerically pure alcohols from renewable starting materials. Admittedly, the product titres achieved in this proof-of-concept study are too low to be economically and environmentally attractive. Further work in our groups will focus on the expansion of this proof-ofconcept experiments for synthetic application, increasing the product yields and the investigation of their biological properties such as anti-microbial activity.

\section{Methods}

Preparation of the biocatalysts. Oleate hydratase from Lactobacillus reuteri $(\mathrm{LrOH})$ was produced via recombinant expression in E. coli BL21 (DE3) cells harbouring pET28a(+) LrOH (Supplementary Fig. 4). These cultures were grown overnight in lysogeny broth (LB) medium, containing $30 \mu \mathrm{g} \mathrm{mL} \mathrm{L}^{-1}$ kanamycin. The pre-cultures were used to inoculate large cultures $\left(1000 \mathrm{~mL} \mathrm{LB}+50 \mu \mathrm{g} \mathrm{mL}^{-1}\right.$ kanamycin in $5 \mathrm{~L}$ shake flasks). Cells were grown at $37^{\circ} \mathrm{C}, 180 \mathrm{rpm}$, until an $\mathrm{OD}_{600}$ 

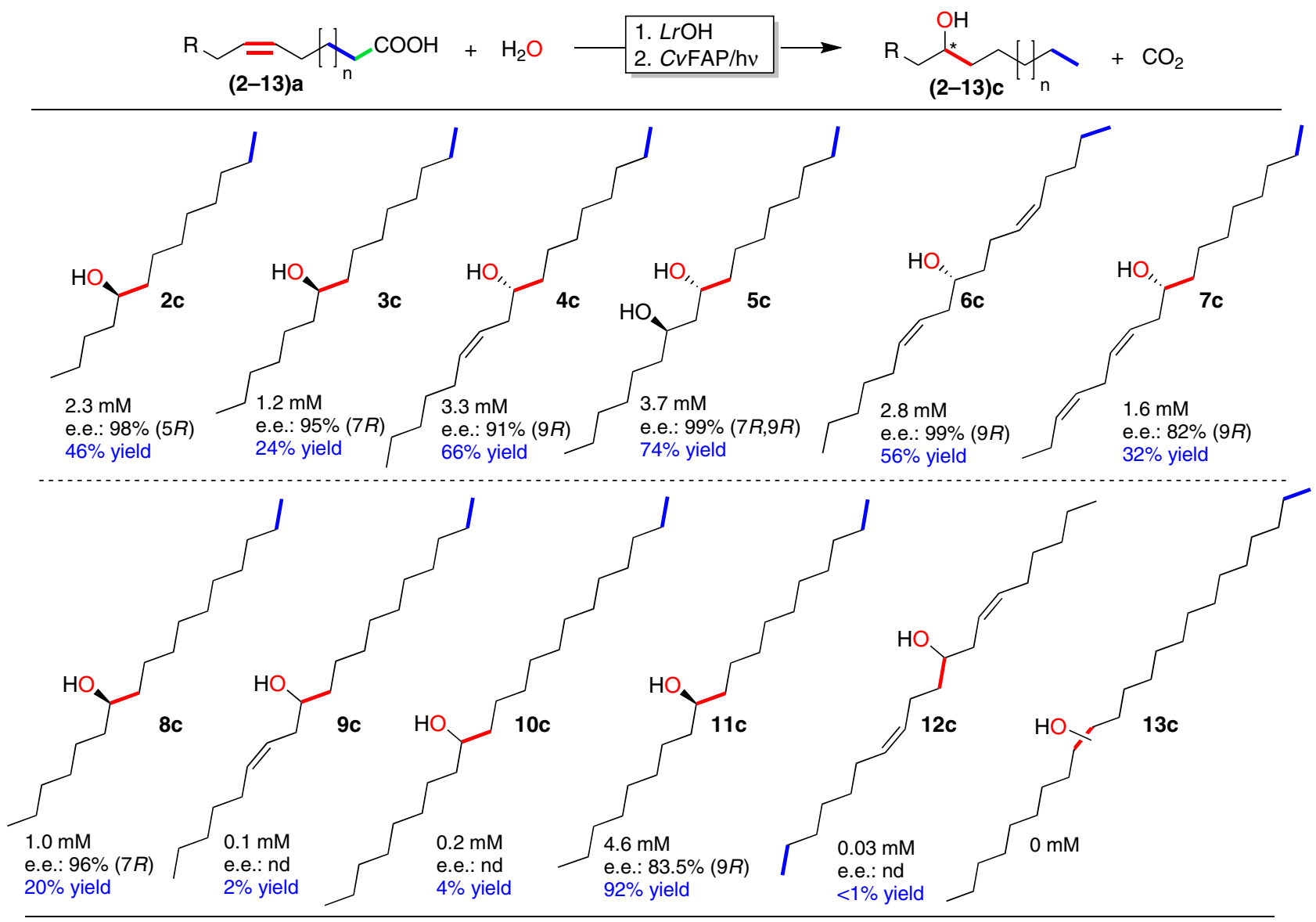

Fig. 4 Preliminary product scope of the proposed photoenzymatic reaction system. Reaction conditions: [substrate] $=5 \mathrm{mM}$, [LrOhyA-cells] $=20 \mathrm{~g} \mathrm{~L}^{-1}$, $[C V F A P]=2 \mu \mathrm{M}$, Tris- $\mathrm{HCl}$ buffer $(100 \mathrm{mM}$, with $50 \mathrm{mM}$ of $\mathrm{NaCl})$, blue light $\left(\lambda=450 \mathrm{~nm}\right.$; intensity $\left.=13.7 \mathrm{mE} \mathrm{L}^{-1} \mathrm{~s}^{-1}\right)$. The reactions were performed in a two-step fashion: first the LrOhyA-catalysed hydration reaction was performed for $11 \mathrm{~h}$ followed by addition of CVFAP and illumination for another $6 \mathrm{~h}$. nd not determined. Conversion $=[\text { product }]_{\text {final }} \times[\text { substrate }]_{\text {initial }}{ }^{-1} \times 100 \%$; determined via GC, conversions determined via ${ }^{1} \mathrm{H}$ NMR are shown in Supplementary Tables 2 and 3. The enantiomeric excess (e.e.) was determined by ${ }^{1} \mathrm{H}$ NMR analysis after the fatty alcohols were derivatised by $(S)-(+)$-Oacetylmandelic acid (details see Supplementary Tables 1 and 2).

between 0.6 and 0.8 was reached. Protein production was induced by the addition of $0.5 \mathrm{mM}$ isopropyl- $\beta$-D-thiogalactopyranoside (IPTG) (final concentration) and the cells were left at $20^{\circ} \mathrm{C}, 180 \mathrm{rpm}$, for overnight $(18 \mathrm{~h})$. Cells were harvested by centrifugation $\left(11,000 \times g\right.$ at $4{ }^{\circ} \mathrm{C}$ for $\left.10 \mathrm{~min}\right)$, washed with Tris- $\mathrm{HCl}$ buffer $(50$ $\mathrm{mM}, \mathrm{pH} 7.5,100 \mathrm{mM} \mathrm{NaCl})$ and centrifuged again. The cell pellets were collected and stored at $-80^{\circ} \mathrm{C}$ for further use. The expression level of $\mathrm{LrOH}$ was found to be rather reproducible $(9.7 \pm 1 \mathrm{mg} L r \mathrm{OH}$ per gram cell dry weight) from various expression experiments at different scales $(50 \mathrm{~mL}$ to $9.6 \mathrm{~L})$.

5,8-Diol synthase from Aspergillus nidulans (AnDS) was expressed in E. coli BL21(DE3) by using the recombinant plasmids (i.e, pET21a-AnDS ${ }^{33}$ and pACYCPelBSS-AnDS) (see the SI for details). The recombinant E. coli cultures were grown overnight in terrific broth (TB) medium containing the appropriate antibiotics. The pre-cultures were used to inoculate large cultures ( $500 \mathrm{~mL}$ in $2 \mathrm{~L}$ shake flasks). The cells were grown at $37^{\circ} \mathrm{C}, 180 \mathrm{rpm}$ until an $\mathrm{OD}_{600}$ between 0.6 and 0.8 was reached. Protein production was induced by the addition of $0.1 \mathrm{mM}$ IPTG and the cells were left at $16^{\circ} \mathrm{C}, 150 \mathrm{rpm}$ for overnight. The resulting cells were harvested by centrifugation and used as the biocatalysts for dihydroxylation of oleic acid (Fig. 7).

The fatty acid photodecarboxylase from Chlorella variabilis NC64A (CvFAP) was produced in E. coli BL21 (DE3) ${ }^{27}$. In short, $10 \mathrm{~mL}$ pre-cultures of E. coli BL21 (DE3) cells harbouring the designed pET28a-His-TrxA-C $v$ FAP plasmid were grown overnight in $\mathrm{TB}$ medium, containing $50 \mu \mathrm{g} \mathrm{mL}^{-1}$ kanamycin. From these, $500 \mathrm{~mL}$ cultures $\left(\mathrm{TB}+50 \mu \mathrm{g} \mathrm{mL}^{-1}\right.$ kanamycin in $2 \mathrm{~L}$ shake flasks) were prepared (cell growth at $37^{\circ} \mathrm{C}, 180 \mathrm{rpm}$, until an $\mathrm{OD}_{600}$ between 0.7 and 0.8 followed by induction by the addition of $0.5 \mathrm{mM}$ IPTG). The cultures were incubated at $17^{\circ} \mathrm{C}$, $180 \mathrm{rpm}$, for another $20 \mathrm{~h}$. Cells were harvested (centrifugation at $11,000 \times g, 4^{\circ} \mathrm{C}$ for $10 \mathrm{~min}$ ) and resuspended directly into the $A n \mathrm{DS}$ reaction medium. Otherwise, the cells, which were harvested (centrifugation at $11,000 \times g, 4^{\circ} \mathrm{C}$ for $10 \mathrm{~min}$ ), were washed with Tris- $\mathrm{HCl}$ buffer $(50 \mathrm{mM}, \mathrm{pH} 8,100 \mathrm{mM} \mathrm{NaCl})$ and centrifuged again. The cell pellet was suspended in the same buffer, and $1 \mathrm{mM}$ PMSF was added. Cells were lysed by passing them passed twice through a Multi Shot Cell Disruption
System (Constant Systems Ltd, Daventry, UK) at 1.5 bar, followed by centrifugation of the cell lysate $\left(38,000 \times g\right.$ at $4{ }^{\circ} \mathrm{C}$ for $\left.1 \mathrm{~h}\right)$. After centrifugation, $5 \%$ glycerol $(\mathrm{w} / \mathrm{v})$ was added to the soluble fraction, the cell extract was aliquoted, frozen in liquid nitrogen and stored at $-80^{\circ} \mathrm{C}$.

The total protein content of the cell extract was determined by a BCA Assay (Interchim), using BSA as a standard. C $v$ FAP production was analysed by sodium dodecyl sulfate-polyacrylamide gel electrophoresis using a Criterion ${ }^{\text {Tx }}$ Cell electrophoresis system (Bio-Rad).

The recombinant $E$. coli BL21(DE3) pACYC-PelBSS-OhyA/pET28a-C $v$ FAP coexpressing $S m$ OhyA and $C v$ FAP were grown overnight in TB medium, containing appropriate antibiotics. From these, $500 \mathrm{~mL}$ cultures (TB + appropriate antibiotics in $2 \mathrm{~L}$ shake flasks) were prepared (cell growth at $37^{\circ} \mathrm{C}, 180 \mathrm{rpm}$, until an $\mathrm{OD}_{600}$ between 0.7 and 0.8 followed by induction by the addition of $0.5 \mathrm{mM}$ IPTG). The cultures were incubated at $20^{\circ} \mathrm{C}, 180 \mathrm{rpm}$, for another $20 \mathrm{~h}$. Cells were harvested (centrifugation at $11,000 \times g, 4^{\circ} \mathrm{C}$ for $10 \mathrm{~min}$ ) and resuspended directly into the Tris-HCl buffer $(50 \mathrm{mM}, \mathrm{pH} 8,100 \mathrm{mM} \mathrm{NaCl})$ for biotransformation.

General procedures for cascade reactions. Experiments were performed as independent duplicates. In all, $2.5-20 \mathrm{mg}$ of lyophilised E. coli cells of oleate hydratase, and $2.0 \mathrm{mg}$ of oleic acid were added into $980 \mu \mathrm{L}$ of Tris- $\mathrm{HCl}$ buffer $(100 \mathrm{mM}$, with $50 \mathrm{mM}$ of $\mathrm{NaCl}$ ) for the hydratase-decarboxylase cascade reaction (Fig. 2). The resultant suspension was stirred at $30^{\circ} \mathrm{C}$ for $11 \mathrm{~h} .20 \mu \mathrm{L}$ of photodecarboxylase (from stock solution with a concentration of $102 \mu \mathrm{M}$ ) was added afterwards and the suspension was illuminated with blue LED light and stirred for another $6 \mathrm{~h}$. The final reaction conditions were: Reaction condition: [substrate] = $7 \mathrm{mM}$, [lyophilised $\mathrm{LrOH}$ cells] $=2.5-20 \mathrm{mg} \mathrm{mL}^{-1},[\mathrm{C} v \mathrm{FAP}]=2 \mu \mathrm{M}$, Tris- $\mathrm{HCl}$ buffer (pH 8.0, $100 \mathrm{mM}$, with $50 \mathrm{mM}$ of $\mathrm{NaCl}$ ), blue light (intensity $=13.7 \mathrm{mE} \mathrm{L}^{-1}$ $\mathrm{s}^{-1}$ ), total volume $1.0 \mathrm{~mL}$. To analyse the product, $1 \mathrm{~mL}$ of ethyl acetate (containing $5 \mathrm{mM}$ of 1-octanol) was added to the above reaction suspension (1:1 volume ratio) $\rightarrow 3 \mathrm{~mL}$ of ethyl acetate (containing $5 \mathrm{~g} / \mathrm{L}$ of palmitic acid) was 


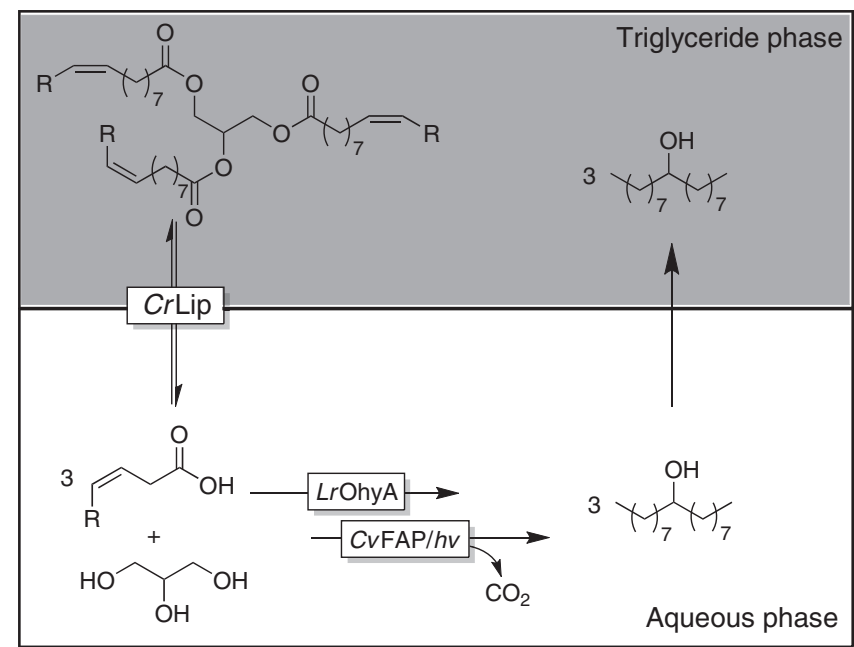

Fig. 5 Trienzymatic cascade for the transformation of triolein into 9heptadecanol using a two-liquid-phase approach. The aqueous reaction medium is supplemented with neat triolein (triglyceride phase) serving as substrate reservoir and product sink. In the reaction sequence, triolein is hydrolysed by the lipase from Candida rugosa (CrLip, located at the interphase) liberating glycerol and oleic acid. The latter is hydrated and decarboxylated (catalysed by LrOHyA and CVFAP) yielding 9-heptadeconol, which partitions back into the hydrophobic phase. added to the above reaction suspension (3:1 volume ratio) The organic phase was collected by centrifugation and was dried over $\mathrm{MgSO}_{4}$. The obtained sample was analysed by gas chromatography (GC) (Cp sil $5 \mathrm{CB}$, column $50 \mathrm{~m} \times 0.53 \mathrm{~mm} \times$ $1.0 \mu \mathrm{m})$.

For the photoenzymatic SmOhyA-hydration and $\mathrm{C} v$ FAP-decarboxylation of oleic acid, recombinant E. coli BL21 (DE3) pACYC-PelBSS-OhyA/pET28a-CvFAP was added into $50 \mathrm{mM}$ Tris- $\mathrm{HCl}$ buffer (pH 6.5) containing $5 \mathrm{mM}$ oleic acid. For the reaction, first the SmOhyA-catalysed hydration reaction was performed for $0.125 \mathrm{~h}$ followed by CvFAP-catalysed decarboxylation under illumination for another $1.625 \mathrm{~h}$. The final reaction conditions were: reaction condition: [oleic acid $]=5 \mathrm{mM}$, $[$ E. coli co-expressing SmOhyA and $C v \mathrm{FAP}]=7 \mathrm{~g} \mathrm{~L}^{-1}$, Tris- $\mathrm{HCl}$ buffer $\mathrm{pH} 6.5(50 \mathrm{mM})$, illumination with blue light $(\lambda=450 \mathrm{~nm}$; intensity $=$ $\left.13.7 \mathrm{mE} \mathrm{L}^{-1} \mathrm{~s}^{-1}\right)$.

For the photoenzymatic diol synthesis-decarboxylation of oleic acid (Fig. 7), $7 \mathrm{mg}$ E. coli cells containing 5,8-diol synthase ( $A n \mathrm{DS}$ cells) and $7 \mathrm{mg}$ of oleic acid were added into $980 \mu \mathrm{L}$ of HEPES buffer $\mathrm{pH} 7.5(50 \mathrm{mM}$, with $10 \%$ (v/v) DMSO). The resultant suspension was stirred at $40^{\circ} \mathrm{C}$ for $2 \mathrm{~h}$. Afterwards, $7 \mathrm{mg} \mathrm{E}$. coli cells containing photodecarboxylase ( $\mathrm{C} v \mathrm{FAP}$ cells) was added and the suspension was illuminated with blue LED light and stirred for another $7 \mathrm{~h}$. The final reaction conditions were: [oleic acid $]=15 \mathrm{mM},[$ AnDS cells $]=7 \mathrm{~g} \mathrm{~L}^{-1},[C v$ FAP cells $]=7 \mathrm{~g} \mathrm{~L}^{-1}$, HEPES buffer $\mathrm{pH} 7.5$ $(50 \mathrm{mM}$, with $10 \%(\mathrm{v} / \mathrm{v}) \mathrm{DMSO})$, blue light (intensity $\left.=13.7 \mathrm{mE} \mathrm{L}^{-1} \mathrm{~s}^{-1}\right)$, total volume $1 \mathrm{~mL}$. To analyse the product, $3 \mathrm{~mL}$ of ethyl acetate (containing $5 \mathrm{~g} \mathrm{~L}^{-1}$ of palmitic acid as internal standard) was added to the above reaction suspension (3:1 volume ratio) and vigorously mixed. The organic phase was collected by centrifugation and was dried over $\mathrm{MgSO}_{4}$. The obtained sample was analysed by gas

chromatography/mass spectrometry $(\mathrm{GC} / \mathrm{MS})^{15,35}$. The results are included in the Supplementary Fig. 51).

Preparative-scale synthesis starting from linoleic acid. 98 millilitres of Tris$\mathrm{HCl}$ buffer (pH 8.0, $100 \mathrm{mM}$, with $50 \mathrm{mM}$ of $\mathrm{NaCl}$ ) containing $10 \mathrm{mM}$ of substrate and $2 \mathrm{~g}$ of lyophilised $\mathrm{LrOH}$ cells were mixed in a beaker and stirred at $30^{\circ} \mathrm{C}$ for
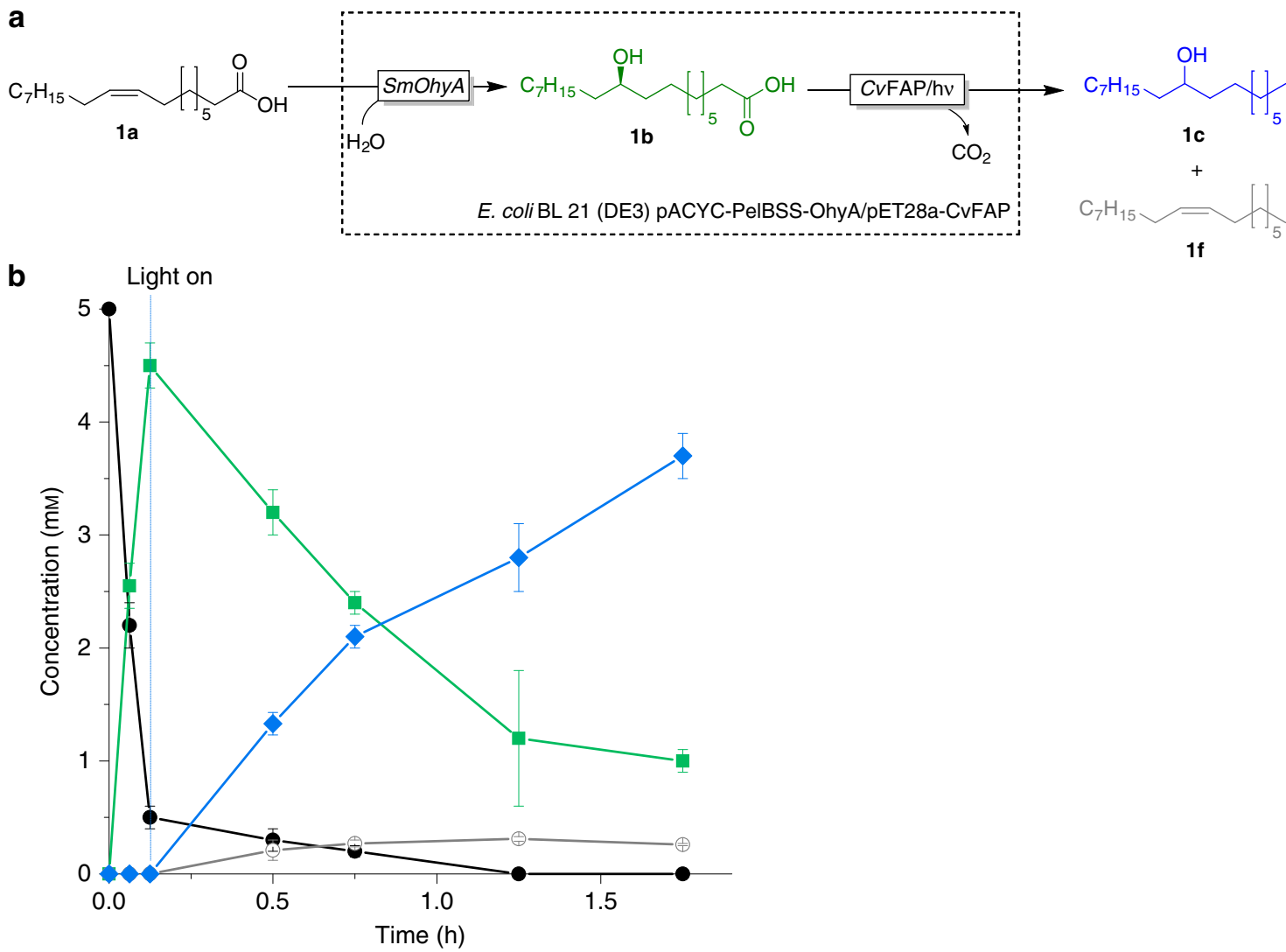

Fig. 6 Photoenzymatic cascade. a Reaction scheme of the photoenzymatic cascade combining SmOhA and CvFAP in a single expression host. b Time course of the conversion of oleic acid using co-expressed enzymes. Oleic acid (1/a, black circles) was converted via 10-hydroxystearic acid ( $\mathbf{1 b}$, green squares) into 9-heptadecanol (1c, blue diamonds) and the side-product ( $Z$ )-heptadec-8-ene (1f, grey empty circles) using the freshly designed, all-inclusive E. coli BL21 (DE3) pACYC-PelBSS-OhyA/pET28a-CvFAP. [oleic acid] $=5 \mathrm{mM}$, [E. coli co-expressing SmOhyA and CVFAP] $=7 \mathrm{~g}$ dry cells L ${ }^{-1}$, Tris-HCl buffer pH $6.5(50 \mathrm{mM})$, illumination with blue light $\left(\lambda=450 \mathrm{~nm}\right.$; intensity $\left.=13.7 \mathrm{mE} \mathrm{L}^{-1} \mathrm{~s}^{-1}\right)$. For the reaction, first the SmOhyA-catalysed hydration reaction was performed for $0.125 \mathrm{~h}$ followed by CVFAP-catalysed decarboxylation under illumination for another $1.625 \mathrm{~h}$. Values represent the average of duplicates $(n=2)$. Error bars indicate the standard deviation. 
a

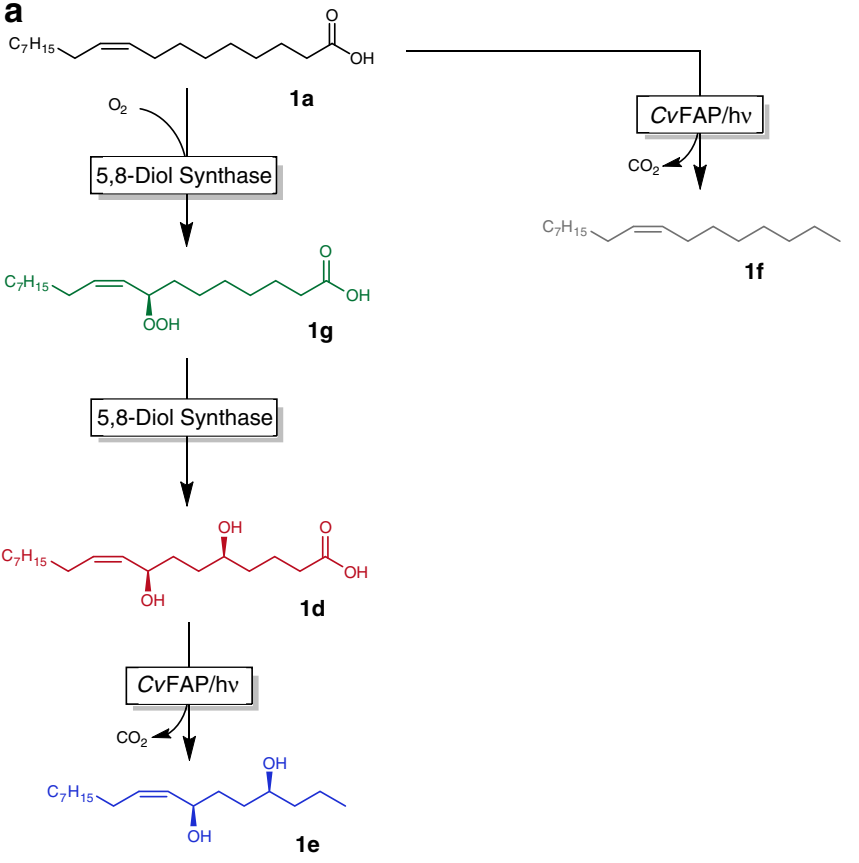

b

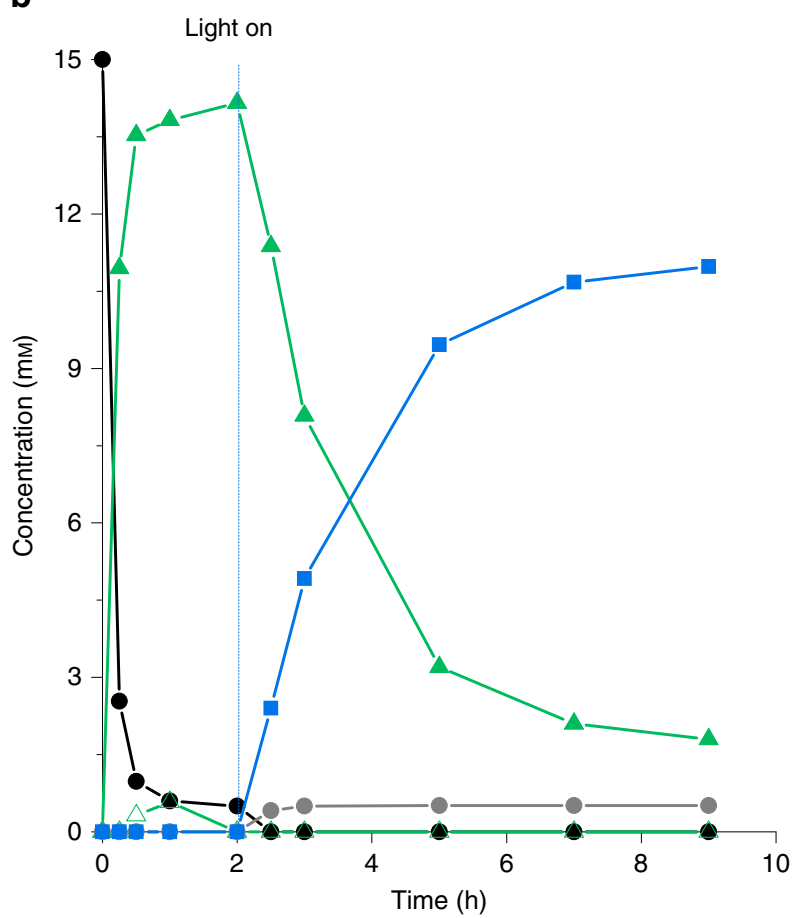

Fig. 7 Photoenzymatic cascade. a Reaction scheme of the photoenzymatic cascade transforming oleic acid into Photoenzymatic diol synthesisdecarboxylation of oleic acid. b Typical time course [oleic acid] $=15 \mathrm{mM},\left[\right.$ AnDS cells] $=7 \mathrm{~g} \mathrm{~L}^{-1}$, [CvFAP cells] $=7 \mathrm{~g} \mathrm{~L}^{-1}, \mathrm{HEPES}$ buffer pH 7.5 (50 mM, with 10\% (v/v) DMSO), illumination with blue light $\left(\lambda=450 \mathrm{~nm}\right.$; intensity $\left.=13.7 \mathrm{mE} \mathrm{L}^{-1} \mathrm{~s}^{-1}\right)$ : oleic acid (black circles), 8 -hydroperoxy-9(Z)-octadecenoic acid (19, green empty triangles), 5,8-dihydroxy-9(Z)-octadecenoic acid (1d, green triangles), (4S,7R,Z)-heptadec-8-ene-4,7-diol (1e, blue squares), (Z)heptadec-8-ene (1ff, grey circles). For the reaction, first the AnDS-catalysed diol synthetic reaction was performed for $2 \mathrm{~h}$ followed by addition of $C v F A P$ and illumination for another $7 \mathrm{~h}$. The absolute configuration is based on the enantioselectivity of the synthase as previously established by Oh and coworkers 28,48 .

$48 \mathrm{~h}$. The beaker was sealed by using parafilm. Two millilitres of photodecarboxylase (from stock solution with a concentration of $102 \mu \mathrm{M}$ ) was added afterwards and the suspension was illuminated by blue LED and stirred for $48 \mathrm{~h}$ The final reaction condition was: [linoleic acid] $=10 \mathrm{mM}$, [lyophilised $\mathrm{LrOH}$ cells] $=20 \mathrm{mg} \mathrm{mL}^{-1},[C \nu \mathrm{FAP}]=2 \mu \mathrm{M}$, Tris- $\mathrm{HCl}$ buffer $(\mathrm{pH} 8.0,100 \mathrm{mM}$, with $50 \mathrm{mM}$ of $\mathrm{NaCl}$ ), blue light (intensity $=13.7 \mathrm{mE} \mathrm{L}^{-1} \mathrm{~s}^{-1}$ ), total volume $1.0 \mathrm{~mL}$. At the end of the cascade reactions, the mixture was extracted with ethyl acetate $(75 \mathrm{~mL}, 2 \times)$. The extraction solvent of the combined phases was removed under reduced pressure. The crude product was purified via flash chromatography (liquid loading) on silica gel using heptane/ethyl acetate 40:1 as eluent for $15 \mathrm{~min}$, followed by a programmed gradient for $10 \mathrm{~min}$ (ethyl acetate/heptane ( 2.5 to $80 \%$ ethyl acetate/ heptane gradient). $82.5 \mathrm{mg}$ (32.5\% isolated yield) of the corresponding alcohol was obtained starting from linoleic acid.

Reporting summary. Further information on research design is available in the Nature Research Reporting Summary linked to this article.

\section{Data availability}

The data that support the findings of this study are available from the corresponding authors upon reasonable request. The source data underlying Figs. 3, 6, 8 and Supplementary Figs. 7 and 25 are provided as a Source data file.

Received: 30 July 2019; Accepted: 9 April 2020;

Published online: 07 May 2020

\section{References}

1. Straathof, A. J. J. Transformation of biomass into commodity chemicals using enzymes or cells. Chem. Rev. 114, 1871-1908 (2013).

2. Bozell, J. J. \& Petersen, G. R. Technology development for the production of biobased products from biorefinery carbohydrates-the US Department of Energy's “Top 10” revisited. Green. Chem. 12, 539-554 (2011).
3. Aransiola, E. F. et al. A review of current technology for biodiesel production: state of the art. Biomass-. Bioenergy 61, 276-297 (2014).

4. Ansorge-Schumacher, M. B. \& Thum, O. Immobilised lipases in the cosmetics industry. Chem. Soc. Rev. 42, 6475-6490 (2013).

5. Rude, M. A. et al. Terminal olefin (1-alkene) biosynthesis by a novel P450 fatty acid decarboxylase from Jeotgalicoccus species. Appl. Environ. Microbiol. 77, 1718-1727 (2011).

6. Pickl, M. et al. Mechanistic studies of fatty acid activation by CYP152 peroxygenases reveal unexpected desaturase activity. ACS Catal. 9, 565-577 (2018).

7. Wang, J. et al. Exploring substrate scope and stereoselectivity of P450 peroxygenase OleTJE in olefin-forming oxidative decarboxylation. Chem. Commun. 52, 8131-8133 (2016).

8. Rui, Z. et al. Microbial biosynthesis of medium-chain 1-alkenes by a nonheme iron oxidase. Proc. Natl Acad. Sci. 111, 18237-18242 (2014).

9. Bojarra, S. et al. Bio-based $\alpha, \omega$-functionalized hydrocarbons from multi-step reaction sequences with bio- and metallo-catalysts based on the fatty acid decarboxylase OleTJE. ChemCatChem 10, 1192-1201 (2018).

10. Zachos, I. et al. Photobiocatalytic decarboxylation for olefin synthesis. Chem. Commun. 51, 1918-1921 (2015).

11. Dennig, A. et al. Enzymatic oxidative tandem decarboxylation of dioic acids to terminal dienes. Eur. J. Org. Chem. 21, 3473-3477 (2016).

12. Dennig, A. et al. Oxidative decarboxylation of short-chain fatty acids to 1alkenes. Angew. Chem. Int. Ed. 54, 8819-8822 (2015).

13. $\mathrm{Wu}, \mathrm{S}$. et al. Chemo-enzymatic cascades to produce cycloalkenes from biobased resources. Nat. Commun. 10, 5060 (2019).

14. Baraibar, A. G. et al. A one-pot cascade reaction combining an encapsulated decarboxylase with a metathesis catalyst for the synthesis of bio-based antioxidants. Angew. Chem. Int. Ed. 55, 14823-14827 (2016).

15. Urlacher, V. B. \& Girhard, M. Cytochrome P450 monooxygenases in biotechnology and synthetic biology. Trends Biotechnol. 37, 882-897 (2019).

16. Wang, Y. et al. Peroxygenases en route to becoming dream catalysts. What are the opportunities and challenges? Curr. Opin. Chem. Biol. 37, 1-9 (2017).

17. Hofrichter, M. \& Ullrich, R. Oxidations catalyzed by fungal peroxygenases. Curr. Opin. Chem. Biol. 19, 116-125 (2014). 
18. Maeng, J. H. et al. Diversity of dioxygenases that catalyze the first step of oxidation of long-chain n-alkanes in Acinetobacter sp. M-1. FEMS Microbiol. Lett. 141, 177-182 (1996).

19. Resch, V. \& Hanefeld, U. The selective addition of water. Catal. Sci. Technol. 5, 1385-1399 (2015).

20. Engleder, M. et al. Structure-based mechanism of oleate hydratase from Elizabethkingia meningoseptica. ChemBioChem 16, 1730-1734 (2015).

21. Nanda, S. \& Yadav, J. S. Lipoxygenase biocatalysis: a survey of asymmetric oxygenation. J. Mol. Catal. B: Enzym. 26, 3-28 (2003).

22. Seo, E. -J. et al. Enzyme/whole-cell biotransformation of plant oils, yeast derived oils, and microalgae fatty acid methyl esters into n-nonanoic acid, 9-hydroxynonanoic acid, and 1,9-nonanedioic acid. Biores. Technol. 251, 288-294 (2018).

23. Cha, H. -J. et al. Simultaneous enzyme/whole-cell biotransformation of $\mathrm{C} 18$ ricinoleic acid into (R)-3-hydroxynonanoic acid, 9-hydroxynonanoic acid, and 1,9-nonanedioic acid. Adv. Synth. Catal. 360, 696-703 (2018).

24. Koppireddi, S. et al. Combined biocatalytic and chemical transformations of oleic acid to $\omega$-hydroxynonanoic acid and $\alpha, \omega$-nonanedioic acid. Adv. Synth. Catal. 358, 3084-3092 (2016).

25. Jeon, E. -Y. et al. Simultaneous enzyme/whole-cell biotransformation of plant oils into C9 carboxylic acids. ACS Catal. 6, 7547-7553 (2016).

26. Song, J. -W. et al. Design and engineering of whole-cell biocatalytic cascades for the valorization of fatty acids. Catal. Sci. Technol. 10, 46-64 (2020).

27. Song, J. -W. et al. Multistep enzymatic synthesis of long-chain $\alpha, \omega-$ dicarboxylic and $\omega$-hydroxycarboxylic acids from renewable fatty acids and plant oils. Angew. Chem. Int. Ed. 52, 2534-2537 (2013).

28. Seo, M. -J. et al. Production of 5,8-dihydroxy-9(Z)-octadecenoic acid from oleic acid by whole recombinant cells of Aspergillus nidulans expressing diol synthase. Biotechnol. Lett. 37, 131-137 (2015).

29. Estupiñán, M. et al. Unveiling the genes responsible for the unique Pseudomonas aeruginosa oleate-diol synthase activity. Biochim. Biophys. Acta Mol. Cell Biol. Lipids 1841, 1360-1371 (2014).

30. Winkler, M. Carboxylic acid reductase enzymes (CARs). Curr. Opin. Chem. Biol. 43, 23-29 (2018).

31. Ni, Y. et al. A biocatalytic hydrogenation of carboxylic acids. Chem. Commun. 48, 12056-12058 (2012).

32. Zhou, P. et al. Deep eutectic solvents enable more robust chemoenzymatic epoxidation reactions. ChemCatChem 9, 934-936 (2017).

33. Desroches, M. et al. From vegetable oils to polyurethanes: synthetic routes to polyols and main industrial products. Polym. Rev. 52, 38-79 (2012).

34. Davis, C. B. et al. Synthesis and biological evaluation of galactofuranosyl alkyl thioglycosides as inhibitors of mycobacteria. Carbohyd. Res. 342, 1773-1780 (2007).

35. Sugandhi, E. W. et al. Synthesis and antimicrobial activity of symmetrical twotailed dendritic tricarboxylato amphiphiles. Bioorg. Med. Chem. 15 , 3842-3853 (2007).

36. Schmitz, E. et al. Synthesen von trail-pheromonen der pharaoameise (Monomorium pharaonis(L.)). J. Prakt. Chem. 322, 261-272 (1980).

37. Saeki, A. et al. A versatile approach to organic photovoltaics evaluation using white light pulse and microwave conductivity. J. Am. Chem. Soc. 134, 19035-19042 (2012).

38. Sorigué, D. et al. An algal photoenzyme converts fatty acids to hydrocarbons. Science 357, 903-907 (2017).

39. Huijbers, M. et al. Light-driven enzymatic decarboxylation of fatty acids. Angew. Chem. Int. Ed. 57, 13648-13651 (2018).

40. Zhang, W. et al. Hydrocarbon synthesis via photoenzymatic decarboxylation of carboxylic acids. J. Am. Chem. Soc. 141, 3116-3120 (2019).

41. $\mathrm{Wu}, \mathrm{Q}$. et al. Light-driven kinetic resolution of $a$-functionalized carboxylic acids enabled by engineered fatty acid photodecarboxylase. Angew. Chem. Int. Ed. 58, 8474-8478 (2019).

42. Dawes, G. J. S. et al. Deoxygenation of biobased molecules by decarboxylation and decarbonylation-a review on the role of heterogeneous, homogeneous and bio-catalysis. Green. Chem. 17, 3231-3250 (2015).

43. Engleder, M. et al. Evolving the promiscuity of Elizabethkingia meningoseptica oleate hydratase for the regio- and stereoselective hydration of oleic acid derivatives. Angew. Chem. Int. Ed. 58, 7480-7484 (2019).

44. Joo, Y. -C. et al. Production of 10-hydroxystearic acid from oleic acid by whole cells of recombinant Escherichia coli containing oleate hydratase from Stenotrophomonas maltophilia. J. Biotechnol. 158, 17-23 (2012).

45. Kang, W. -R. et al. Gene cloning of an efficiency oleate hydratase from Stenotrophomonas nitritireducens for polyunsaturated fatty acids and its application in the conversion of plant oils to 10-hydroxy fatty acids. Biotechnol. Bioeng. 114, 74-82 (2017).

46. Jung, S. M. et al. Fatty acid hydration activity of a recombinant Escherichia coli-based biocatalyst is improved through targeting the oleate hydratase into the periplasm. Biotechnol. J. 10, 1887-1893 (2015).

47. An, J. -U. et al. Microbial synthesis of linoleate 9S-lipoxygenase derived plant C18 oxylipins from C18 polyunsaturated fatty acids. J. Agric. Food Chem. 67, 3209-3219 (2019).

48. Seo, M. -J. et al. Production of 5,8-dihydroxy-9,12(Z,Z)-octadecadienoic acid from linoleic acid by whole recombinant Escherichia coli cells expressing diol synthase from Aspergillus nidulans. Appl. Microbiol. Biotechnol. 98, 7447-7456 (2014).

49. Lei, S. P. et al. Characterization of the Erwinia carotorova pelB gene and its products pectate lyase. J. Bacteriol. 169, 4379-4383 (1987).

50. Engleder, M. \& Pichler, H. On the current role of hydratases in biocatalysis. Appl. Microbiol. Biotechnol. 102, 5841-5858 (2018).

51. Schrewe, M. et al. Direct terminal alkylamino-functionalization via multistep biocatalysis in one recombinant whole-cell catalyst. Adv. Synth. Catal. 355, 1693-1697 (2013).

\section{Acknowledgements}

The Netherlands Organisation for Scientific Research (NWO) is gratefully acknowledged for financial support through a VICI grant (no. 724.014.003). W.Z. gratefully acknowledges financial support by "Young Talent Support Plan" of Xi'an Jiaotong University (No. 7121191208). This work was also supported by the National Research Foundation of Korea (NRF) grant funded by the Korea government (MEST) (No. 2020R1A2B5B03002376).

\section{Author contributions}

J.B.P., R.K. and F.H. conceived the study, supervised the experimental work and data analysis and wrote the manuscript. W.Z., F.T., Y.B., S.H.H.Y. and J.H.L. performed the reactions and data collection. H.P. and P.L.H. conceptually contributed to the study design. All authors were involved in the composition of the manuscript.

\section{Competing interests}

The authors declare no competing interests.

\section{Additional information}

Supplementary information is available for this paper at https://doi.org/10.1038/s41467 020-16099-7.

Correspondence and requests for materials should be addressed to J.-B.P., R.K. or F.H.

Peer review information Nature Communications thanks Qi Wu and the other, anonymous, reviewer(s) for their contribution to the peer review of this work. Peer reviewer reports are available.

Reprints and permission information is available at http://www.nature.com/reprints

Publisher's note Springer Nature remains neutral with regard to jurisdictional claims in published maps and institutional affiliations.

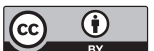

Open Access This article is licensed under a Creative Commons Attribution 4.0 International License, which permits use, sharing, adaptation, distribution and reproduction in any medium or format, as long as you give appropriate credit to the original author(s) and the source, provide a link to the Creative Commons license, and indicate if changes were made. The images or other third party material in this article are included in the article's Creative Commons license, unless indicated otherwise in a credit line to the material. If material is not included in the article's Creative Commons license and your intended use is not permitted by statutory regulation or exceeds the permitted use, you will need to obtain permission directly from the copyright holder. To view a copy of this license, visit http://creativecommons.org/ licenses/by/4.0/

(C) The Author(s) 2020 